\title{
ENT SURGEONS AS MASTER TRAINERS OF CRICOTHYROIDOTOMY WILL SAVE PRECIOUS LIVES IN EMERGENCIES
}

\author{
Syed Muhammad Asad Shabbir Bukhari, Sohail Aslam, Naeem Riaz*, Asim Abbas**, Maqbool Raza***, Ghulam Fareed*** \\ Pakistan Naval Ship Shifa, Karachi Pakistan, *Pakistan Naval Ship Hafeez, Karachi Pakistan, ${ }^{* *}$ Combined Military Hospital Malir/National University of Medical \\ Sciences (NUMS) Pakistan, ${ }^{* * *}$ Combined Military Hospital Multan/National University of Medical Sciences (NUMS) Pakistan
}

\section{ABSTRACT}

Objective: To train young doctors and paramedical staff on needle cricothyroidotomy and surgical cricothyroidotomy and provision of kits in trauma centers, main operation theatres and medical reception centers of the hospitals.

Study Design: Quasi experimental study.

Place and Duration of Study: Combined Military Hospital Peshawar and Pakistan Naval Ship Shifa, Karachi Pakistan, from Nov 2017 to Oct 2020.

Methodology: Doctors and paramedical staff were selected on volunteer basis. Small groups were trained in 2-3hours. The participants were shown two videos of two procedures in Urdu language first and then were trained on mannequin.

Results: A total of 345 participants including 205 males and 140 females were trained with mean age was $28.2667 \pm 6.24$ (SD) years. Out of 61 residents, 54 medical officers, 143 house officers, 35 nurses and 52 paramedical staff were participants.

Conclusion: ENT surgeons must arrange mannequins and conduct training sessions of small groups after every 1 to 2 months.

Keywords: ENT surgeons, Master trainers, Needle cricothyroidotomy.

How to Cite This Article: Bukhari SMAS, Aslam S, Riaz N, Abbas A, Raza M, Fareed G. ENT Surgeons as Master Trainers of Cricothyroidotomy will Save Precious Lives in Emergencies. Pak Armed Forces Med J 2021; 71 (Suppl-3): S504-507. D Doi: https://doi.org/10.51253/pafmj.v1i1.7926

This is an Open Access article distributed under the terms of the Creative Commons Attribution License (https://creativecommons.org/licenses/by-nc/4.0/), which permits unrestricted use, distribution, and reproduction in any medium, provided the original work is properly cited.

\section{INTRODUCTION}

The management of airways during emergency conditions are very challenging for the doctors and paramedical staff. The skill of endotracheal intubation is very important and should be taught regularly by the anesthesiologists to the young doctors and paramedical staff. Anesthesiologists are the medical specialists of airways and the master trainers of endotracheal intubations for young doctors and paramedical staff. ENT surgeons are surgical specialists of airways and trainers of emergency tracheostomies in the past in developing countries like Pakistan. Due to availability of good quality cricothyroidotomy mannequins, the role of ENT surgeons, as master trainers of needle cricothyroidotomy and surgical cricothyroidotomy will be beneficial to whole mankind. They will impart surgical skills to doctors and paramedical staff in peace and their trainees will save precious lives in wars, operational areas and in peace at emergency departments. Cannot ventilate, cannot intubate (CVCI) situations need emergent cricothyroidotomy, but lack of training of doctors can lead to brain deaths of the patients in five minutes. All over the world, few percentage of the patients should be managed by needle cricothyroidotomy or surgical cricothyroidotomy. This percentage is due to difficult intubation and multiple factors. In

Correspondence: Dr Syed Muhammad Asad Shabbir Bukhari, Classified ENT Specialist, PNS Shifa, Karachi Pakistan
Pakistan, the basic responsibility for training should be taken by otorhinolaryngologists. These skills were not easy to teach few years back due to lack of availability of good quality mannequins and proper guidelines. The model of teaching of such abilities is likewise not good in industrialized countries. ${ }^{1}$ Emergency needle and surgical cricothyrodotomies are lifesavingprocedures. Information based evaluation of preparing impacts and expertise levels are identified with all departments associated with airway management in emergencies. $^{2}$

In a study, ultrasound was used to detect cricothyroid membrane, but we detected the membrane with palpation. ${ }^{3}$ The limiting factor for needle cricothyroidotmy was appropriate tube to connect the cannula with oxygen source. The author thought for several years to utilize the local tubing material available in emergent conditions particularly for needle cricothyroidotomy. The needle cricothyroidotomy was made effective by using intravenous tubing of $1000 \mathrm{ml}$ normal saline. It was attached to oxygen source like central oxygen or cylinder and an opening is made in tubing for passive CO2 removal in 4 seconds, after 1214 litres/min of oxygen in 1 second.

Needle cricothyroidtomy was made user friendly with few easy steps and mannequin. Surgical cricothyroidotomy was for all doctors and needle cricothyroidotomy was for all paramedical staff and doctors. 
Many anesthesiologists, particularly during training, lack the surgical skills of cricothyroidotomy and seek help of ENT surgeons. Different commercially available kits of cricothyroidotomy are available, but these are expensive and not available for all medical centers of developing countries. Surgical cricothyroidotomy was made easy in this study by using only two surgical instruments like small curved artery forceps and BP handle with 15 number surgical blade.

The purpose of study was to train young doctors and paramedical staff on needle cricothyroidotomy and surgical cricothyroidotomy and provision of kits in trauma centres, main operation theatres and medical reception centres of the hospitals.

\section{METHODOLOGY}

It was quasi experimental study, carried out at Combined Military Hospital Peshawar and Pakistan Naval Ship Shifa Karachi, from November 2017 to October 2020. Ethical approval was taken for the study from hospital ethics committee.

Sampling technique was non probability convenience. Sampling size was according to availability of human resource for training. All the doctors and paramedical staff having age $>18$ years were included. These were volunteers to learn. All those were not interested in training sessions were excluded. https:// www.youtube.com/watch? $\mathrm{v}=1 \mathrm{U} 8 \mathrm{og} X \mathrm{X}$ 11 go\& $\mathrm{t}=200 \mathrm{~s}$

(Needle cricothyroidotomy). https://www.youtube. com/watch? $v=0$ RvbiayZZtE (Surgical cricothyroidotomy). The above mentioned videos were shown to participants before giving them training. The participant used their cell phone to watch these videos in 9 minutes.

A good quality mannequin was made available along with necessary equipment. The participants were trained by master trainer (author of article). After imparting training, feedback was taken by participants and recorded. Descriptive statistics of SPSS-20 were applied. Frequencies were analysed and mean and standard deviation were calculated.

\section{RESULTS}

A total of 345 participated in the study 205 $(59.4 \%)$ were male and $140(40.6 \%)$ were female. Male to female ratio is shown in Figure. Mean age of the study population was $28.2667 \pm 6.24$ years. Minimum age was 18 years and maximum age was 48 years. Various categories were involved to impart training. These were medical officers,residents, house officers, nurse and paramedic staff. These are shown in Table-I.
After the training, the feedback remarks of participants were recorded in Table-II. Out of $94.2 \%$ of participants strongly recommended these skills for the doctors and paramedical staff as effective for lifesaving in emergencies.

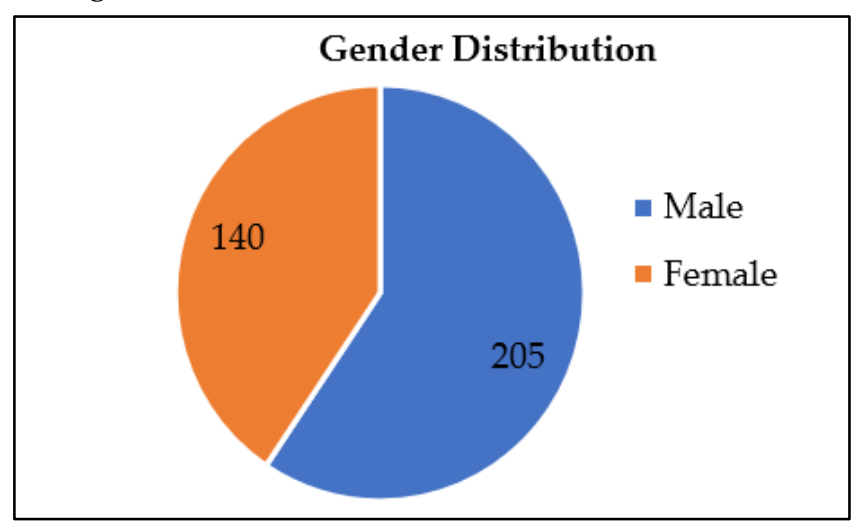

Figure: Gender distribution of study.

Table-I: Categories of participants of study $(n=345)$.

\begin{tabular}{l|c|c}
\hline Category & Frequency & Percentage \\
\hline Residents & 61 & 17.7 \\
\hline House officers & 143 & 41.4 \\
\hline Medical officers & 54 & 15.7 \\
\hline Nurse & 35 & 10.1 \\
\hline Paramedic staff & 52 & 15.1 \\
\hline
\end{tabular}

Table-II: Feedback of participants $(n=345)$.

\begin{tabular}{l|c|c}
\hline Remarks & Frequency & Percentage \\
\hline Strongly recommended & 325 & 94.2 \\
\hline Recommended & 10 & 2.9 \\
\hline Neutral & 3 & 0.9 \\
\hline Indecisive & 4 & 1.2 \\
\hline Not recommended & 3 & 0.9 \\
\hline Total & 345 & 100 \\
\hline
\end{tabular}

\section{DISCUSSION}

Here are different systems to improve the abilities in youngsters of medical profession. The students were first instructed by talks and afterward they saw video. After wards, hands on exercise was given as in one of American specialist preparing program. ${ }^{4}$ Our study followed the comparable way to show the members. Albeit reliable training, period of specialist and years from residency were related with diminished expertise. ${ }^{5}$ In our study, inspiration of participant doctors and paramedical staff added to better aptitude. Practice onmannequin prompted decreases in cricothyroidotomy execution time and improvement in progress rates. After the fifth attempt,in an study, 96\% of members had the option to effectively carried out the cricothyroidotomy in $40 \mathrm{~s}$ or less. ${ }^{6}$ In our study, the members were offered freedom to rehearse the two skills however much possible. They were permitted to return 
again in their extra energy and practice the abilities after few days of workshop.

Length of cricothyroid membrane differs and several studies were done to make the skills stressfree. ${ }^{7} \mathrm{An} 80 \mathrm{~mm}$ incision commencing $30 \mathrm{~mm}$ above the suprasternal notch would include all cricothyroid membrane locations in the extended position in patients without airway pathology in a study. ${ }^{8}$ The advised vertical midline incision length of $80 \mathrm{~mm}$ was significantly long, and that it could cause excessive bleeding and potentially worsen an already high-risk situation. ${ }^{9}$

In emergency, vertical incision is recommended as in our study, we performed vertical incision for surgical cricothyroidotomy. The length on mannequin was kept about $40-50 \mathrm{~mm}$ in extended position. We disagree with $80 \mathrm{~mm}$ incision for surgical cricothyroidotomy. It may lead to more bleeding and complications. Cricothyroidotomy has complication rates from $9-40 \%$ in many studies and can result in a "cannot intubate-cannot oxygenate" situations when the cricothyroid membrane is not properly recognized. ${ }^{10}$ Few doctors use "cannot intubate-cannot ventilate" (CICV) instead of "cannot intubate-cannot oxygenate" (CICO). We believe in same medical condition and same management for $\mathrm{CICV}$ or $\mathrm{CICO}$ but slight difference in terminology.

One of three strategies for recognizing the cricothyroid membrane (palpation of anatomical structures versus a guess dependent on four finger widths versus an assessment dependent on overlying skin wrinkles of the neck). A distinct master evaluator utilized ultrasound to recognize the superior and inferior lines of the cricothyroid membrane. Every one of the three techniques performed inadequately overall. ${ }^{11}$

In our study, palpation of cricothyroid membrane was carried out, by fingers and most of members were victorious in identification. Success in performing surgical cricothyroidotomymight be improved by a superior comprehension of human neck structures, standard practice, improved needle cricothyroidotomy procedure, and the consistent utilization of ultrasound. ${ }^{12}$ Success rates, for right proof of identity of the crico-thyroid membrane, were additionally poor in a Cana-dian foundation. ${ }^{13}$ In reality, ultrasound may help the doctors in emergency departments in the identification of cricothyroid membrane.

Insufficiencies in airway management expertise and judgment add to reduced results. Worldwide training is inconstant in its delivery and need. Quality assurance is restricted in possibly life-saving skills. ${ }^{14}$
We recommend the role of otorhinolaryngologist in quality training of all doctors and paramedical staff. Small group (5-14 participants) workshops on both skills should be performed after 1-2 months in every medical institution of the world. Good quality mannequinand appropriate disposable material should be provided by head of institution. This most important training will develop basic component of the ENT specialty, in addition to general ENT and advanced ENT components, in all over the world. The motivated ENT specialists can bring the revolutionary change in participants and impart them confidence in emergency conditions. This practice will save precious lives in future.

We suggest distinguishing the cricothyroid membrane before enlistment of sedation in all patients by anesthesiologists. Despite the fact that palpation may help in many patients, the remaining patients will require ultra-sonographic recognizable proof. The ultrasonogram machine should be available in all areas where sedation is attempted and where patients with difficult airway could be faced. ${ }^{15}$

Training in surgical blade dealing with abilities and accentuating putting the surgical bladedown before surgical cricothyroidotomy in the indistinct landmarks. Two recommendations could be made. ${ }^{16}$ The Anesthesiologists must be trained by ENT experts for subject skill. A negligibly obtrusive tracheal surgical blade bougie strategy is desirable over a long midline cut, when the trachea is tangible yet the cricothyroid membrane is not palpable. This choice was not made clear in the DAS rules. We suggest third option in "Cannot intubate cannot oxygenate" (CICO) situation which is easier and pratical. The needle cricothyroidomy with wide bore cannula (3 passes or $60 \mathrm{~s}$ ) even in the impalapale situation, as it helps change to pronouncing a $\mathrm{CICO}$, and maintains a strategic distance from the requirement for a profoundly intrusive open procedure in the event that it is fruitful. This skill is easy to learn and apply in real emergencies. The needle cricothyroidotomy is initial step which must be done by all doctors and trained paramedical staff in case of failed endotracheal intubation. This skill is life saving and can be utilized to gain time for surgical cricothyroidotomy. It prevents from brain death and gives 35-40 minutes to treating doctors for further management. An incorporated cannula first way to deal with CICO salvage procedures is a substantial methodology for anesthetists for their patients, and this should to be revealed in the DAS Plan D recommendations. ${ }^{17}$ We recommend the call for help is made at the 
earliest opportunity, and clearly after one unsuccessful intubation effort. ${ }^{18}$ The more qualified doctors in airway management must be called for early surgical cricothyroidotomy in adults. Knowledge with these skills of needle cricothyroidotomy and surgical cricothyroidotomy, transformed the doctors and medical staff, more confident and responsive to help others, in our study.

The DAS pediatric CICO rules remember Trans Tracheal Jet Ventilation (TTJV) as a possibility for kids, one to eight year old. Our study suggest that children less than 12 years should only be managed with needle cricothyroidotomy and surgical cricothyroidotomy should be performed in patients more than 12 years after initial needle cricothyroidotomy. TTJV has been suggested for over twenty years as a possibly lifesaving strategy in a CICO emergency. ${ }^{19}$

\section{LIMITATION OF STUDY}

This study is new for Pakistan and developing nations of the world. This study requiremannequins and number of mannequins are less. The mannequin was imported from Germany and we should manufacture it locally. A good number of doctors are required to train the majority of junior doctors and paramedical staff. The video was uploaded to youtube channel in Urdu language. This video should be translated and taught in various international and national languages for the benefit of humanity.

\section{CONCLUSIONS}

Needle cricothyroidotomy and surgical cricothyroidotomy are life saving skills and must be taught by simplified methods. Needle cricothyroidotomy must be done in all“ Cannot intubate cannot oxygenate" (CICO) situations, followed by surgical cricothyoidotomy in patients more than 12 years of age.

ENT surgeons must arrange mannequins and conduct training sessions of small groups after every 1-2 months in all hospitals and medical centers. They can impart good quality training to participants leading to save precious lives. This most important practice will develop basic component of the ENT specialty.

\section{Conflict of Interest: None.}

\section{Authors' Contribution}

SMASB: Master trainer and collection of data, SA: Introduction, NR: Mathology, AA: Discussion, MR: Results, GF: Review of literature

\section{REFERENCES}

1. Demirel D, Butler KL, Halic T, Sankaranarayanan G, Spindler D, Cao C, et al. A hierarchical task analysis of cricothyroidotomy procedure for a virtual airway skills trainer simulator. Am J Surg 2016; 212(3): 475-484.

2. Melchiors J, Todsen T, Nilsson P, Wennervaldt K, Charabi B, Bøttger $M$, et al. Preparing for emergency: a valid, reliable asse- ssment tool for emergency cricothyroidotomy skills.Otolaryngol. Head Neck Surg 2015; 152(2): 260-265.

3. Yıldız G, Göksu E, Şenfer A, Kaplan A. Comparison of ultrasonography and surface landmarks in detecting the localization for cricothyroidotomy. Am J Emerg Med 2016; 34(2): 254-256.

4. Jayaraman V, Feeney JM, Brautigam RT, Burns KJ, Jacobs LM. The use of simulation procedural training to improve self-efficacy, knowledge, and skill to perform cricothyroidotomy.Am Surg 2014; 80(4): 377-381.

5. Siu LW, Boet S, Borges BC, Bruppacher HR, LeBlanc V, Naik $\mathrm{VN}$, et al. High-fidelity simulation demonstrates the influence of anesthesiologists' age and years from residency on emergency cricothyroidotomy skills. Anesth Analg 2011; 111(4): 955-960.

6. Wong DT, Prabhu AJ, Coloma M, Imasogie N, Chung FF. What is the minimum training required for successful cricothyroidotomy? A study in mannequins. Anesthesiol 2003; 98(2): 349-353.

7. Fennessy P, Drew T, Husarova V, Duggan M, McCaul CL. Emergency cricothyroidotomy: an observational study to estimate optimal incision position and length. Br J Anaesth 2019; 122(2): 263-268.

8. Fennessy P, Aslani A, Campbell M, Husarova V, Duggan M, McCaul CL. Theoretical optimal cricothyroidotomy incision length in female subjects, following identification of the cricothyroid membrane by digital palpation. Int J Obstet Anesth 2018; 36(1): $42-48$.

9. Miller TC, Comara J, Groom P. Simulated emergency cricothyroid incision length. Br J Anaesth 2017; 119(2): 340- 341.

10. Siddiqui N, Arzola C, Friedman Z, Guerina L, You-Ten KE. Ultrasound improves cricothyrotomy success in cadavers with poorly defined neck anatomy: a randomized control trial. Surv Anesthesiol 2016; 60(4): 177-178.

11. Bair AE, Chima R. The inaccuracy of using landmark techniques for cricothyroid membrane identification: a comparison of three techniques.AcadEmerg Med 2015; 8(2): 908-914.

12. Elliott DS, Baker PA, Scott MR, Birch CW, Thompson JM. Accuracy of surface landmark identification for cannula cricothyroidotomy. Anaesth 2010; 65(9): 889-894.

13. Lamb A, Zhang J, Hung O, Flemming B, Mullen T, Bissell MB, et al. Accuracy of identifying the cricothyroid membrane by anesthesia trainees and staff in a Canadian institution. Can J Anaesth Can J Anesth 2015; 62(5): 495-503.

14. Armstrong L, Harding F, Critchley J, McNarry AF, Myatra SN, Cooper R, et al. An international survey of airway management education in 61 countries. Br J Anaesth 2020; 125(1):e54-60.

15. Kristensen MS, Teoh WH, Rudolph SS. Ultrasonographic identification of the cricothyroid membrane: best evidence, techniq ues, and clinical impact. Br J Anaesth 2016; 117(Suppl-1): i39-48.

16. Pairaudeau CF, Mendonca C, Hillermann C, Qazi I, Baker PA, Hodgson RE, et al. Effect of palpable vs. impalpable cricothyroid membranes in a simulated emergency frontofneck access scenario. Anaesth 2018; 73(5): 579-586.

17. Heard A, Dinsmore J, Douglas S, Lacquiere D. Plan D: cannula first, or scalpel only?. Br J Anaesth 2016; 117(4): 533-535.

18. Higgs A, McGrath BA, Goddard C, Rangasami J, Suntharalingam G, Gale R, Cook TM, Society DA. Guidelines for the management of tracheal intubation in critically ill adults. Br J Anaesth 2018; 120(2): 323-352.

19. Duggan LV, Ballantyne Scott B, Law JA, Morris IR, Murphy MF, Griesdale DE. Transtracheal jet ventilation in the 'can't intubate can't oxygenate'emergency: a systematic review.Br J Anaesth 2016; 117(suppl-1): I28-38. 